\title{
Unraveling the Mechanism of Propanoic Acid Hydrodeoxygenation on Palladium using Deuterium Kinetic Isotope Effects
}

\author{
Yuliana K. Lugo-José, Sina Behtash, Marjorie Nicholson, John R. Monnier, \\ Andreas Heyden and Christopher T. Williams*
}

Department of Chemical Engineering, University of South Carolina, Columbia, SC 29208

* To whom correspondence should be addressed:

\author{
Christopher T. Williams \\ Department of Chemical Engineering \\ Swearingen Engineering Center \\ University of South Carolina \\ Columbia, SC 29208 \\ Phone: (803)777-0143 \\ Fax: (803)777-8265 \\ E-mail:willia84@cec.sc.edu
}




\begin{abstract}
A combined experimental and computational kinetic isotope effect (KIE) study was performed for the catalytic hydrodeoxygenation (HDO) of deuterium-labeled propanoic acid (PAc-2, 2-D2) over Pd catalyst. For the experimental study, the kinetics were measured in a plug flow reactor over a $5 \mathrm{wt} \% \mathrm{Pd} / \mathrm{C}$ catalyst at $200^{\circ} \mathrm{C}$ and 1 atm under differential conversion using a reactor feed consisting of $1.2 \%$ PAc and $5 \%$ or $20 \% \mathrm{H}_{2}$, with balance helium. Different experimental KIE values for the high $\left(\mathrm{k}_{\mathrm{H}} / \mathrm{k}_{\mathrm{D}}=1.13 \pm 0.04\right)$ and low $\left(\mathrm{k}_{\mathrm{H}} / \mathrm{k}_{\mathrm{D}}=1.62 \pm 0.05\right)$ partial pressures of hydrogen were observed. Density functional theory calculations were performed to obtain the reaction parameters of the elementary steps involved in the HDO of PAc on Pd (111), and a microkinetic model was developed to estimate the KIE for the low hydrogen partial pressure case from first principles. The computed result $\left(\mathrm{k}_{\mathrm{H}} / \mathrm{k}_{\mathrm{D}}=1.49\right)$ is in good agreement with the experiment. In addition, the product distribution favored $\mathrm{C}_{2} \mathrm{H}_{6}$ and $\mathrm{CO}$, suggesting decarbonylation $(\mathrm{DCN})$ is the main reaction pathway. This provides strong evidence for the proposed mechanism for the formation of $\mathrm{C}_{2} \mathrm{H}_{6}$ on both $\mathrm{Pd}$ (111) and supported Pd nanoparticles presenting primarily that exposed crystal face.
\end{abstract}

\title{
Keywords
}

Kinetic Isotope Effect; Density functional theory; Propanoic acid; Dehydrogenation; Palladium 


\section{Introduction}

An extensive amount of research has explored the catalytic performance for the hydrodeoxygenation (HDO) of biomass-derived carboxylic acids and acid esters [1, 2]. Supported palladium is one of the most investigated catalysts in the area of catalytic hydrodeoxygenation of biomass-derived platform molecules [3-14]. For instance, early studies showed that supported palladium offers a strong activity and selectivity for the HDO of PAc [1519]. While kinetic studies reveal overall reaction rates, reaction orders, and apparent activation barriers, they do not provide enough information for determining the fundamental elementary steps involved in the reaction mechanism [20, 21]. For HDO reactions, the network of these underlying steps is complex and not yet fully understood.

In our previous DFT studies [22-24] the HDO of PAc was investigated over Pd (111) model surfaces. The elementary reaction steps involved in the decarbonylation (DCN) and decarboxylation (DCX) were identified from first principles (Figure 1). A microkinetic model was developed to determine the dominant pathway and rate-controlling steps under realistic reaction conditions of $200{ }^{\circ} \mathrm{C}$ and low, medium, and high partial pressures of hydrogen $(0.001,1$ and 30 bar) in the presence and absence of solvents. Our results suggest that under gas phase reaction conditions, $\mathrm{DCN}$ is favored over the DCX, while in the presence of water, DCN and DCX mechanisms become essentially competitive [22]. This is in agreement with our experimental study of the gas-phase HDO of PAc over supported group VIII noble metals, where we found that on various metals the DCN pathway dominates [25]. 


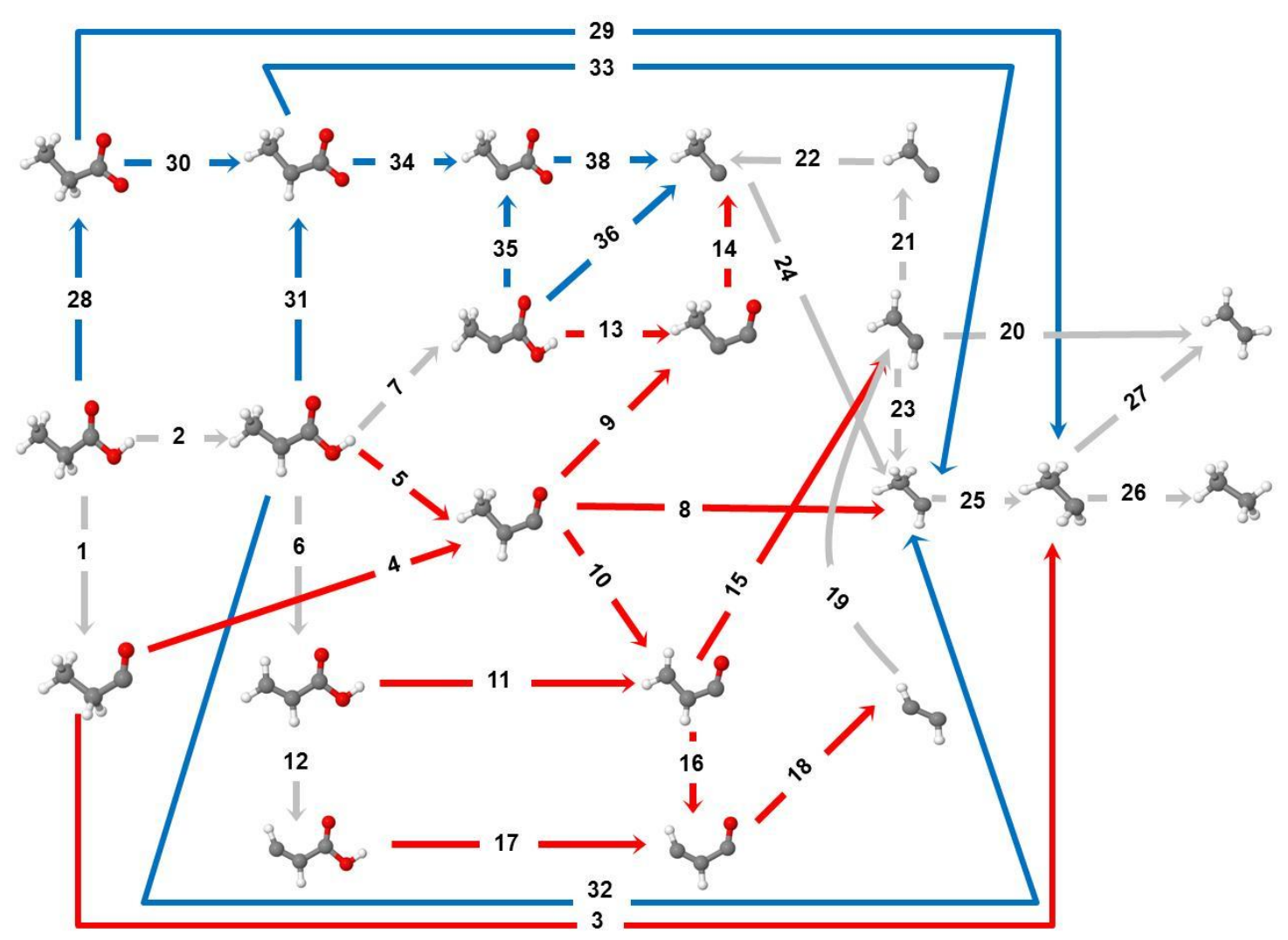

Figure 1. Network of elementary reaction steps considered in the hydrodeoxygenation of PAc over Pd (111). Elementary reactions involved in the DCX mechanism are shown with blue color arrows, DCN reactions are illustrated with red color arrows, and those reactions involved in both mechanisms such as dehydrogenation reactions and removal of the hydrocarbon pool are shown with gray color arrows.

Additionally, computations found that in all reaction environments, and at a low hydrogen partial pressure, dehydrogenation of the $\alpha$-carbon in PAc is the primary rate-controlling step. With increasing hydrogen partial pressure, $\mathrm{C}-\mathrm{OH}$ bond dissociation becomes the rate-controlling and the importance of $\mathrm{C}-\mathrm{H}$ bond cleavage is diminished [22]. The dissociation of the $\mathrm{C}-\mathrm{OH}$ bond is one of the key reactions in the DCN and was previously also identified as the rate-determining step for the HDO of acetic acid [26, 27]. Our studies, however, clearly suggest that at all 
conditions, dehydrogenation steps of the $\alpha$-carbon of the acid have at least some importance for the HDO of the acid to hydrocarbons. Barteau et al. and Zhong et al. have also examined the deoxygenation of carboxylic acids over $\operatorname{Pd}[1,28,29]$. They suggest that a carboxylate intermediate undergoes dehydrogenation, which is accompanied by $\mathrm{C}-\mathrm{O}$ bond cleavage, resulting in $\mathrm{CO}$ and hydrocarbon formation by $\mathrm{C}-\mathrm{C}$ bond cleavage. Similar work has been reported previously, such as the experimental work of Maier et al. on the gas-phase deoxygenation of octanoic acid [30] and recent computational work on the DCX of butanoic acid by Lamb et al. Their work suggested that dehydrogenation of the $\alpha$-carbon occurs during DCN/DCX of aliphatic carboxylic acids over Pd [31].

The present study explores the deuterium kinetic isotope effect (KIE) [32-39] for the HDO of PAc in order to further confirm the importance of $\mathrm{C}-\mathrm{H}$ bond cleavage in the reaction pathway. PAc substituted with deuterium at the $\alpha$-carbon position $\left(\mathrm{CH}_{3} \mathrm{CD}_{2} \mathrm{COOH}\right)$ was deoxygenated over $5 \mathrm{wt} \% \mathrm{Pd} / \mathrm{C}$ catalyst and its reaction rate and TOF compared with that obtained from unlabeled PAc $\left(\mathrm{CH}_{3} \mathrm{CH}_{2} \mathrm{COOH}\right)$. From these data, experimental rate constant ratio $\left(k_{\mathrm{H}} / k_{\mathrm{D}}\right)$ was determined under various hydrogen partial pressures. Density functional theory (DFT) calculations were performed for labeled PAc and its intermediates on Pd (111) to obtain the reaction parameters of all the elementary steps involved. The DFT-derived parameters were then implemented in a microkinetic model that allowed prediction of $k_{\mathrm{H}} / k_{\mathrm{D}}$ under the same conditions used for the experiments. The experimental and computational results are consistent with each other, and confirm the importance of $\mathrm{C}-\mathrm{H}$ bond cleavage in governing the rates of HDO of PAc on Pd. 


\section{Experimental Section}

\subsection{Materials and Catalyst characterization}

The experimental conditions have been previously reported in detail and thus will only be discussed briefly [16]. Propanoic Acid $\left(\mathrm{CH}_{3} \mathrm{CH}_{2} \mathrm{COOH}, 99 \%\right)$ and propanoic acid-2, 2-d2 $\left(\mathrm{CH}_{3} \mathrm{CD}_{2} \mathrm{COOH}, 98 \%\right)$ were purchased from Alfa Aesar and Cambridge Isotope Laboratories, respectively, and used without further purification. The gases for the reactor studies were $\mathrm{H}_{2}$ (UHP), He (UHP,99.99\%), Ar (UHP, 99.99\%) and ethane (CP grade, 99.99\%) supplied by

Airgas National Welders. The $5 \mathrm{wt} \% \mathrm{Pd} / \mathrm{C}$ catalyst $\left(\mathrm{CP}-97, \mathrm{SA}_{\mathrm{BET}}=615 \mathrm{~m}^{2 /} \mathrm{g}\right)$ was supplied by BASF and reduced in-situ at $350^{\circ} \mathrm{C}$. The dispersion (16.9\%) and mean particle size $(6.8 \mathrm{~nm})$ of $5 \mathrm{wt} \% \mathrm{Pd} / \mathrm{C}$ was determined by pulsed hydrogen titration of oxygen pre-covered sites utilizing a Micromeritics 2920 AutoChem II Analyzer. Additionally, analysis based on Van Hardeveld and Hartog statistics suggests that for a $6.8 \mathrm{~nm}$ particle size, $70-72 \%$ of exposed Pd faces correspond to $\operatorname{Pd}(111)$, whereas only $16-17 \%$ correspond to $\operatorname{Pd}(100)$, with the remaining sites made up from corners and edges (which were found to be essentially inactive) [25].

\subsection{Reaction Evaluation}

The reaction experiments were performed in a single pass, packed bed, plug flow reactor system connected to a GC system (Supporting Information, Scheme S.1). The experiments were carried out under differential $(<5 \%)$ conversion at $200^{\circ} \mathrm{C}$ under atmospheric pressure. Two sets of experiments were conducted: (1) $1.2 \% \mathrm{PAc} / 20 \% \mathrm{H}_{2} /$ balance $\mathrm{He}$ and (2) $1.2 \% \mathrm{PAc} / 5 \% \mathrm{H}_{2} /$ balance He in a total flow of $50 \mathrm{sccm}$. This catalyst under these reaction conditions has previously been shown to be free of both external and internal mass transfer effects [16]. In addition, the carbon support was tested separately and found to exhibit no activity at these reaction conditions [16]. The reaction rate was determined based on the formation of product (which is proportional to the rate of acid disappearance) in $\mu \mathrm{mol}$ product formed $/ \mathrm{min} \cdot \mathrm{g}_{\mathrm{cat}}$. The turn over frequency (TOF) was 
determined based on the reaction rate per active site in $\min ^{-1}$ of the $5 \mathrm{wt} \% \mathrm{Pd} / \mathrm{C}$ catalyst. Unlabeled and labeled PAc were kept in separate vapor-liquid equilibrium (VLE) saturators (Supporting Information, Scheme S.1) and the concentrations of the both acids (e.g. labeled and unlabeled) in the gas feed were set equal prior to starting the reaction. Once the reaction with unlabeled PAc reached steady-state, the reactor feed was switched to the labeled PAc. This process was cycled until steady state reaction was attained for each species. In this way, the KIE can be determined as the ratio between the unlabeled and labeled TOF (i.e., $k_{\mathrm{H}} / k_{\mathrm{D}}$ ). Carbon mass balances closed to within $1 \%$ in all the experiments and the activity was stable (i.e., no deactivation was observed) over the entire course of the reaction time on stream.

Measurements of the isotopic composition of the products were conducted by mass spectroscopy. To ensure only the products were analyzed by MS, the PAc (unreacted) was condensed in a cold trap $\left(-55^{\circ} \mathrm{C}\right)$ (Supporting Information, Scheme S.1). This was verified by analyzing the gas effluent with gas chromatography to confirm only products such as $\mathrm{C}_{2} \mathrm{H}_{6}$ and $\mathrm{CO}$ were detected. The gas products were diluted with argon carrier gas (for a total of $50 \mathrm{sccm}$ ) before being sampled by a Stanford Research Systems Residual Gas Analyzer (RGA100) mass spectrometer with an electron multiplier. The detailed description of this apparatus and sampling procedure is included in the Supplemental Information. The masses 29, 30 and 31 were monitored to track various ethane species, while water, nitrogen, oxygen, hydrogen and argon were also monitored to rule out leakage. For the MS study the PAc conversion was increased $(\sim 10 \%)$ by adjusting the catalyst loading $(0.9 \mathrm{~g})$.

\subsection{Computational Methodology}

All density functional theory calculations have been conducted with the Vienna Ab Initio Simulation Package (VASP) [41-43]. The Kohn-Sham valence states are expanded in a plane 
wave basis sets with an energy cut-off of up to $400 \mathrm{eV}$. The interaction between core electrons is described with the projector-augmented wave (PAW) $[43,44]$ method. The exchange correlation energy is calculated within the generalized gradient approximation (GGA) using the functional form proposed by Perdew and Wang, which is known as Perdew-Wang 91 (PW91) [45-47]. Similar pseudopotentials were used for hydrogen and deuterium atoms with only the mass modified for deuterium atoms.

The lattice constant obtained from the optimization of the fcc-Pd bulk is $3.953 \AA$, which is in reasonable agreement with the experimental value of $3.891 \AA$. The surface Brillouin zone is sampled with $4 \times 4 \times 2$ Monkhorst-pack k-point grid. Pd (111) is modeled by a 4-layer slab with a $(3 \times 4)$ surface unit cell and the palladium layers separated by a $15 \AA$ vacuum.

The bottom two layers were fixed to their bulk configuration during all calculations while the top two layers were free to relax in all directions. Adsorption energies of all intermediates were calculated at their most stable geometry by the following equation:

$$
E_{\text {ads }}=E_{\text {slab+adsorbate }}-E_{\text {slab }}-E_{\text {adsorbate }}(g)
$$

where $E_{\text {slab+adsorbate }}$ is the total energy of the adsorbed intermediate on the Pd slab, $E_{\text {slab }}$ is the total energy of the Pd slab and $E_{\text {adsorbate }}(\mathrm{g})$ is the total energy of the adsorbate in the gas phase.

Transition states were obtained from our previous DFT studies [22-24] on PAc and finally, vibrational frequency calculations have been performed to obtain the frequency modes for all labeled intermediates and transition state structures.

The zero-point energy correction for all the structures was taken into account by using the following equation:

$$
\Delta E_{Z P E}=\sum_{i} \frac{1}{2} h v_{i}
$$

where $h$ is the Plank constant and $v_{i}$ is the vibrational frequency of mode $i$. 


\subsubsection{Microkinetic modeling}

For surface reactions, the forward rate constant $\left(k_{\text {for }}\right)$ of each reaction is calculated as:

$$
k_{f o r}=\frac{k_{B} T}{h} \frac{q_{T S, v i b}}{q_{I S, v i b}} e^{\frac{-E_{a_{-} f o r}}{k_{B} T}}
$$

where $k_{\mathrm{B}}$ is the Boltzmann constant, $T$ denotes the reaction temperature, $h$ is the Planck constant, $E_{\text {a_for }}$ stands for the zero-point-energy-corrected activation barrier for the forward reaction derived from DFT calculations, and $q_{\mathrm{TS} \text {,vib }}$ and $q_{\mathrm{IS} \text {,vib }}$ are the (harmonic) vibrational partition functions for the transition state and the initial state, respectively, i.e., $q_{\text {vib }}$ is calculated as:

$$
q_{v i b}=\prod_{i} \frac{1}{1-e^{\frac{-h v_{i}}{k_{B} T}}}
$$

where $v_{i}$ is the vibrational frequency of each vibrational mode of the adsorbed intermediate derived from our DFT calculations.

The reverse rate constant $\left(k_{\text {rev }}\right)$ is calculated similarly and the thermodynamic equilibrium constant $K$ is given by:

$$
K=\frac{k_{f o r}}{k_{\text {rev }}}
$$

For an adsorption reaction $\mathrm{A}(\mathrm{g})+^{*} \rightarrow \mathrm{A}^{*}$, the equilibrium constant $K$ is defined as:

$$
K=\frac{\left(q_{v i b}\right)_{A^{*}}}{\left(q_{v i b} q_{\text {rot }} q_{\text {trans }}\right)_{A(g)}} e^{\frac{-\Delta E_{a d s}}{k_{B} T}}
$$

where $\left(q_{\mathrm{vib}}\right)_{\mathrm{A}^{*}}$ is the vibrational partition function of adsorbed $\mathrm{A}$, and $q_{\mathrm{vib}}, q_{\mathrm{rot}}, q_{\mathrm{trans}}$ stand for vibrational, rotational, and translational partition functions, respectively. $\Delta E_{\text {ads }}$ represents the zero-point corrected adsorption energy. 
For an adsorption reaction $\mathrm{A}(\mathrm{g}){ }^{*} \rightarrow \mathrm{A}^{*}$, the forward rate is given by collision theory with a sticking probability of 1 .

$$
k_{f o r}=\frac{1}{N_{0} \sqrt{2 \pi m_{A} k_{B} T}}
$$

where $N_{0}$ is the number of sites per area $\left(1.478 \times 10^{19} \mathrm{~m}^{-2}\right)$ and $m_{\mathrm{A}}$ denotes the molecular weight of A.

The reverse rate constant is again given as:

$$
k_{\text {rev }}=\frac{k_{\text {for }}}{K}
$$

With the forward and reverse rate constants defined, we solve the full set of steady-state rate equations to obtain the surface coverage of all possible reaction intermediates and the fraction of free sites using the BzzMath library[48] developed by Buzzi-Ferraris. No assumptions were made regarding rate-controlling steps.

\section{Results and Discussion}

\subsection{Kinetic Isotope Effect Measurements}

Figure 2A shows the results of the TOF over time during switching between unlabeled $\left(\mathrm{CH}_{3} \mathrm{CH}_{2} \mathrm{COOH}\right)$ and labeled $\left(\mathrm{CH}_{3} \mathrm{CD}_{2} \mathrm{COOH}\right) \mathrm{PAc}$ at $200^{\circ} \mathrm{C}$ and $1 \mathrm{~atm}$ with a reactor feed of $1.2 \% \mathrm{PAc} / 20 \% \mathrm{H}_{2} /$ balance He. The reaction resulted in differential conversion $(<5 \%)$ with a $100 \%$ selectivity toward $\mathrm{C}_{2} \mathrm{H}_{6}$ (i.e., there were no side products), with $\mathrm{CO}$ indicating decarbonylation $(\mathrm{DCN})$ as the major reaction pathway as described previously [16]. The reaction rates based on the products formed and TOF are summarized in Table 1. The labeled PAc TOF $\left(0.015 \pm 0.001 \mathrm{~min}^{-1}\right)$ was calculated from the 

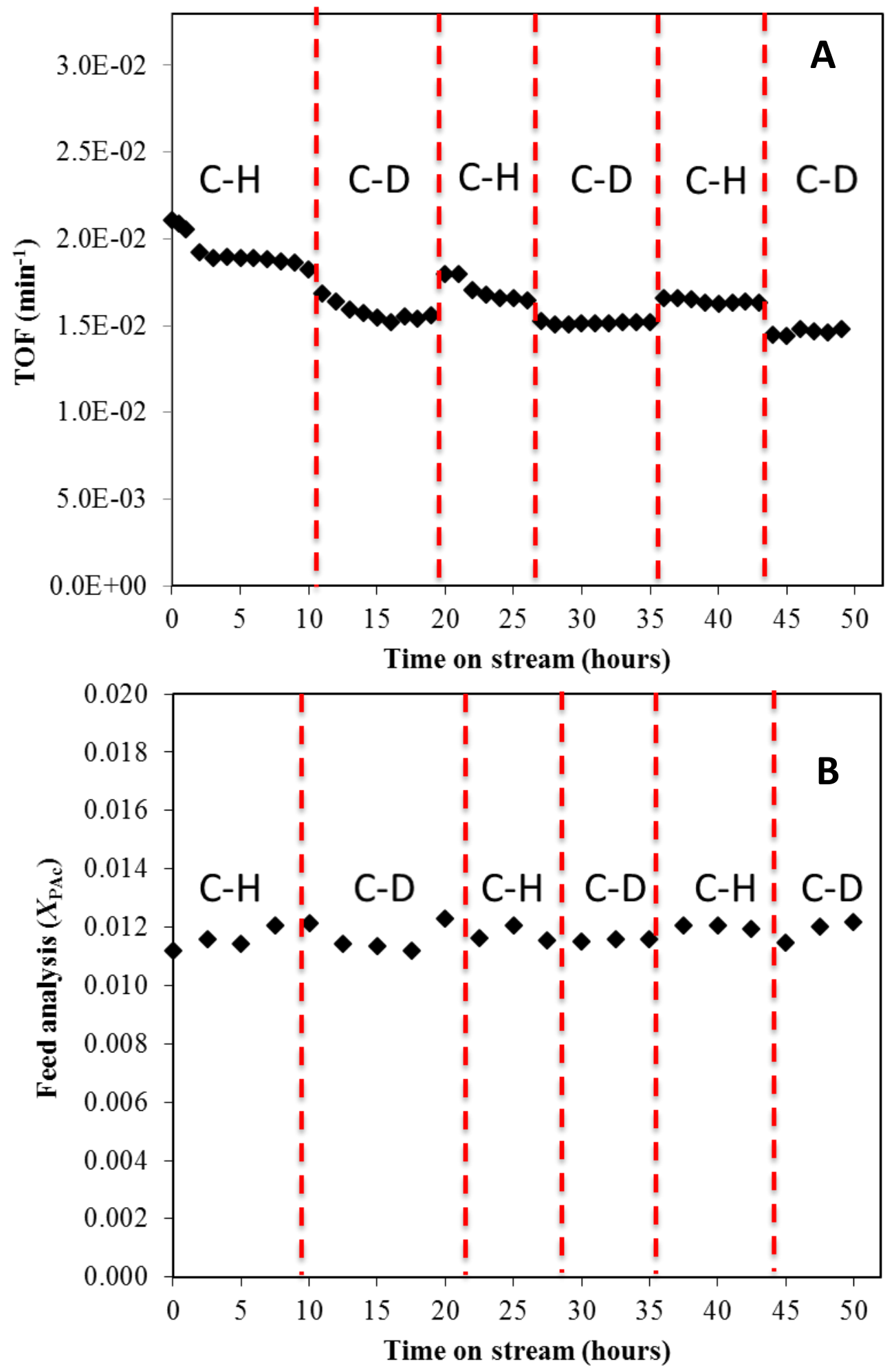

Figure 2. A) TOF measurements as a function of time on stream for HDO during switching between unlabeled (C-H) and labeled (C-D) PAc. B) Feed analysis as a function of time on stream during the same experiment. Reaction conditions: $200^{\circ} \mathrm{C}, 1 \mathrm{~atm}, \sim 1.2 \% \mathrm{PAc}, 20 \% \mathrm{H}_{2}$, balance He. 
Table 1. Deuterium isotope effect for PAc HDO over $5 \mathrm{wt} \% \mathrm{Pd} / \mathrm{C}$. Reaction conditions: $200^{\circ} \mathrm{C}$ and $1 \mathrm{~atm}$, Total flow: $50 \mathrm{sccm}$. $<5 \%$ conversion, $100 \%$ selectivity $\mathrm{C}_{2} \mathrm{H}_{6}{ }^{\mathrm{a}}{ }^{\mathrm{a}} \mathrm{Rxn}$ rate $\mu \mathrm{mol} / \mathrm{min} \cdot \mathrm{g}_{\text {cat }}$. Rxn $1=\mathrm{CH}_{3} \mathrm{CH}_{2} \mathrm{COOH} / \mathrm{H}_{2}, \mathrm{Rxn} 2=\mathrm{CH}_{3} \mathrm{CD}_{2} \mathrm{COOH} / \mathrm{H}_{2}$.

\section{$20 \% \mathrm{H}_{2} /$ balance $\mathrm{He} \quad 5 \% \mathrm{H}_{2} /$ balance $\mathrm{He}$}

\begin{tabular}{|c|c|c|c|c|c|c|c|c|}
\hline $\mathbf{R x n}$ & $\begin{array}{c}\text { Feed conc. } \\
(\% P A c)\end{array}$ & Rxn rate $^{a}$ & $\begin{array}{c}\text { TOF } \\
\left(\mathrm{min}^{-1}\right)\end{array}$ & $\begin{array}{l}k_{\mathrm{H}} / k_{\mathrm{D}} \\
\text { Exp. }\end{array}$ & $\begin{array}{l}\text { Feed conc. } \\
(\% P A c)\end{array}$ & Rxn rate $^{a}$ & $\begin{array}{c}\text { TOF } \\
\left(\mathrm{min}^{-1}\right)\end{array}$ & $\begin{array}{l}k_{\mathrm{H}} / k_{\mathrm{D}} \\
\text { Exp. }\end{array}$ \\
\hline 1 & $1.19 \pm 0.02$ & $1.61 \pm 0.16$ & $0.018 \pm 0.002$ & & $1.22 \pm 0.02$ & $1.28 \pm 0.15$ & $0.016 \pm 0.002$ & \\
\hline 2 & $1.16 \pm 0.03$ & $1.39 \pm 0.05$ & $0.015 \pm 0.001$ & $1.13 \pm 0.04$ & $1.23 \pm 0.01$ & $0.80 \pm 0.09$ & $0.010 \pm 0.001$ & $1.62 \pm 0.05$ \\
\hline
\end{tabular}

average of measurements between 45 and $50 \mathrm{hr}$ on stream, while the unlabeled PAc TOF $\left(0.018 \pm 0.0 .002 \mathrm{~min}^{-1}\right)$ was calculated from the average of measurements between 37 and $44 \mathrm{hrs}$ on stream. Taking the ratio of these two values, the KIE effect was found to be $k_{\mathrm{H}} / k_{\mathrm{D}}=1.13$ \pm 0.04 . Given this small value, as a comparison, Figure $2 \mathrm{~B}$ shows the measurement of acid feed concentration (labeled and unlabeled PAc) as a function of time during the same experiment. The feed concentration analysis were conducted every $\sim 2.5$ hours to verify there was no change. The variability from labeled to unlabeled feed composition is around $3.0 \%$ and a mass balance between $0.99-1.02$ is obtained. Given that the reaction order with respect to PAc is $\sim 0.5$ order under these conditions [16], such variability does not account for the observed rate difference. Nevertheless, this small ratio of $k_{\mathrm{H}} / k_{\mathrm{D}}=1.13 \pm 0.04$, indicates that the isotopic substitution at the $\alpha$-carbon position had little effect under these conditions.

In our previous DFT study, we performed a sensitivity analysis on HDO of propionic acid over Pd (111) model surfaces [22, 23]. Our model suggested that by lowering the partial pressures of hydrogen, the influence of the dehydrogenation of $\alpha$-carbon on the overall TOF will increase. To 
further explore the KIE effect and trend in its relationship with partial pressure of hydrogen, steady-state measurements at $200^{\circ} \mathrm{C}$ and 1 atm total pressure were conducted at lower hydrogen partial pressure. Figure $3 \mathrm{~A}$ shows the TOF data as a function of time during switching between unlabeled and labeled PAc using a feed consisting of $1.2 \% \mathrm{PAc} / 5 \% \mathrm{H}_{2} / \mathrm{balance}$ He. The labeled PAc TOF $\left(0.010 \pm 0.001 \mathrm{~min}^{-1}\right)$ was calculated from the average of measurements between 16 and $19 \mathrm{hr}$ on stream, while the unlabeled PAc TOF $\left(0.016 \pm 0.002 \mathrm{~min}^{-1}\right)$ was calculated from the average of measurements between 19.5 and $23 \mathrm{hrs}$ on stream. A $k_{\mathrm{H}} / k_{\mathrm{D}}$ ratio of $1.62 \pm 0.05$ is obtained, suggesting that a significant KIE is present at this lower partial pressure of hydrogen. Once again, Figure 3B shows the measurement of acid feed concentration as a function of time during the same experiment, revealing negligible variation. The significant KIE therefore indicates that the rate-controlling step involves dehydrogenation of the $\alpha$-carbon (i.e., $\mathrm{C}$-H bond breaking). Indeed, a lower partial pressure of hydrogen should allow for the dehydrogenation of the $\alpha$-carbon to occur to a greater extent, accounting for the increased KIE.

\subsection{Kinetic Isotope Effect Calculations}

The positive experimental KIE values obtained above point to the kinetic importance of $\alpha$-carbon dehydrogenation in the HDO of PAc. According to our previous DFT studies [22, 23], we know that the dehydrogenation of the $\alpha$-carbon is not the only rate-controlling step under the investigated reaction conditions of $200^{\circ} \mathrm{C}$ and partial pressures of 0.01 bar of acid and 0.05 bar of $\mathrm{H}_{2}$. Indeed, the observation that the $k_{\mathrm{H}} / k_{\mathrm{D}}$ ratio varies under different reaction conditions appears to be similar to the changes in the computed degree of rate control [49] of the $\alpha$-carbon dehydrogenation. Thus, the interpretation of the observed KIE is not straightforward. To initially obtain a meaningful range for the KIE in our system, two limiting theoretical cases were considered. In Section 3.2.1, an upper limit for the KIE is predicted for the case where $\alpha$-carbon 

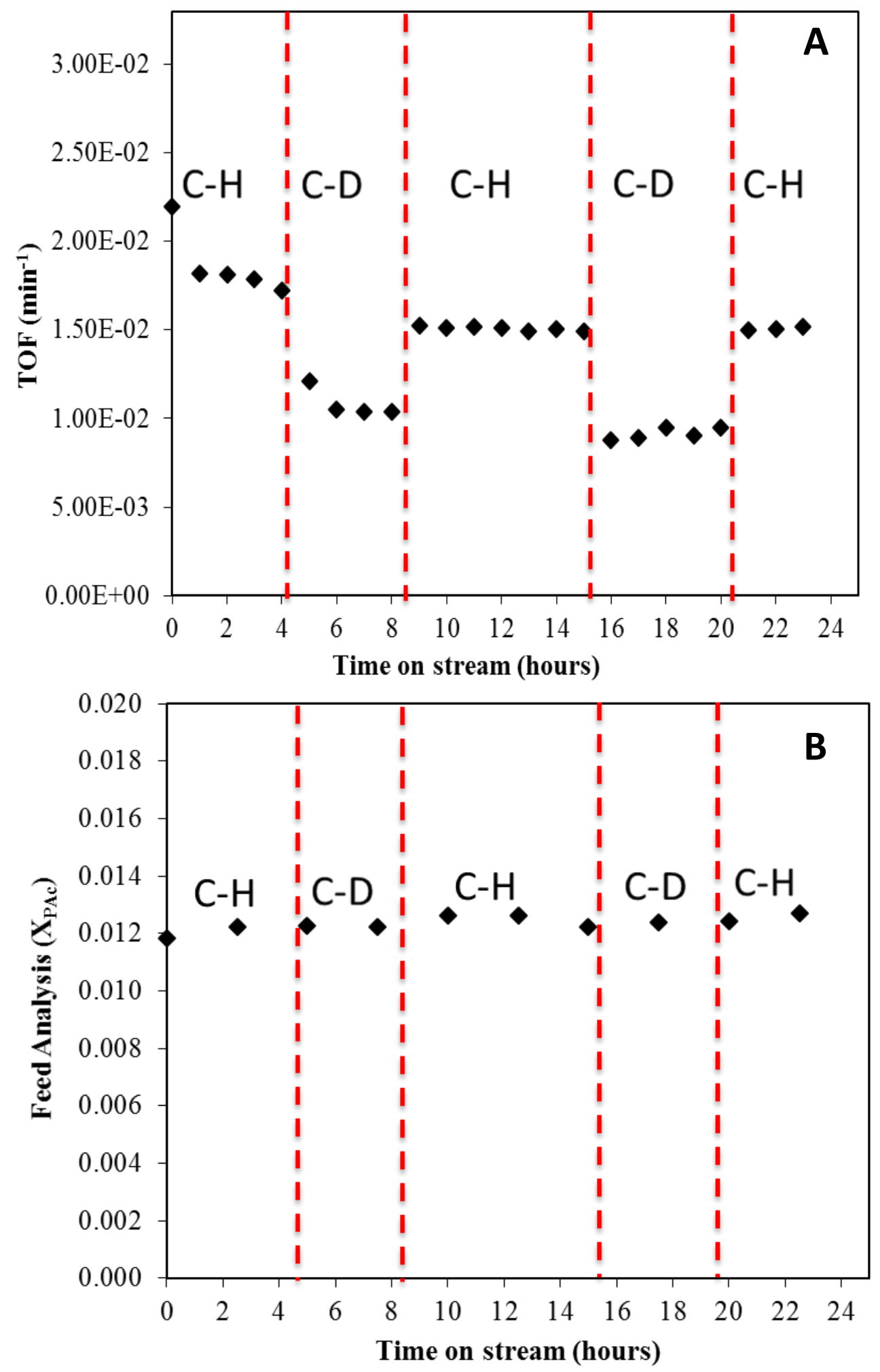

Figure 3. A) TOF measurements as a function of time on stream for HDO during switching between unlabeled $(\mathrm{C}-\mathrm{H})$ and labeled (C-D) PAc. B) Feed analysis as a function of time on stream during the same experiment. Reaction conditions: $200^{\circ} \mathrm{C}, 1 \mathrm{~atm}, \sim 1.2 \% \mathrm{PAc}, 5 \% \mathrm{H}_{2}$, balance He. 
dehydrogenation is the only rate-controlling step. Next, in Section 3.2.2, it is shown that the $k_{\mathrm{H}} / k_{\mathrm{D}}$ ratio is expected to be approximately 1.0 when $\mathrm{C}-\mathrm{H}$ bond dissociation is not rate controlling. While labeling PAc could in principle affect other rate-controlling steps through a secondary kinetic isotope effect, this is also shown to be negligible in this system for the limiting case of $\mathrm{C}-\mathrm{OH}$ bond dissociation being the rate limiting step. Finally, Section 3.2.3 presents a detailed DFT and microkinetic modeling study to estimate the KIE under reaction conditions for a Pd (111) surface from first principles.

\subsubsection{Upper Limit for the Primary Kinetic Isotope Effect}

Assuming that the dehydrogenation of the $\alpha$-carbon is the only rate controlling step in the HDO of PAc, the ratio of the turn over frequencies of $\mathrm{CH}_{3} \mathrm{CH}_{2} \mathrm{COOH}$ and $\mathrm{CH}_{3} \mathrm{CD}_{2} \mathrm{COOH}$ can be approximated using transition state theory as [50-52]:

$$
\frac{\mathrm{TOF}_{\mathrm{CH}_{3} C \mathrm{CH}_{2} \mathrm{COOH}}}{\mathrm{TOF}_{\mathrm{CH}} \mathrm{CD}_{2} \mathrm{COOH}} \approx \frac{k_{H}}{k_{D}} \approx \frac{e^{\frac{-\left(E_{a}+\Delta Z P E_{H}\right)}{K_{B} T}}}{e^{\frac{-\left(E_{a}+\Delta Z P E_{D}\right)}{K_{B} T}}}=e^{\frac{-h}{2 K_{B} T} v_{H}\left(\frac{v_{D}}{v_{H}}-1\right)}
$$

where $E_{\mathrm{a}}$ is the activation barrier, $\triangle Z P E_{\mathrm{H}}$ is the zero-point energy correction to the activation barrier for the unlabeled PAc, $\triangle Z P E_{\mathrm{D}}$ is the zero-point energy correction to the activation barrier for the labeled PAc and $v_{\mathrm{H}}$ and $v_{\mathrm{D}}$ are the C-H and C-D (in the $\alpha$-carbon position) vibrational frequencies, respectively, in PAc.

The maximum $\mathrm{C}-\mathrm{H}$ frequency for $\alpha$-carbons observed in carboxylic acids [53] is $3000 \mathrm{~cm}^{-1}$. In addition,

$$
\frac{v_{D}}{v_{H}} \approx \sqrt{\frac{\mu_{H}}{\mu_{D}}} \quad, \quad \frac{1}{\mu_{H}}=\frac{1}{m_{H}}+\frac{1}{m_{\mathrm{CH}_{3} \mathrm{CHCOOH}}} \text {, and } \frac{1}{\mu_{D}}=\frac{1}{m_{D}}+\frac{1}{m_{\mathrm{CH}_{3} \mathrm{CDCOOH}}}
$$


where $\mu_{\mathrm{D}}$ and $\mu_{\mathrm{H}}$ are the reduced masses for $\mathrm{CH}_{3} \mathrm{CDCOOH}-\mathrm{D}$ and $\mathrm{CH}_{3} \mathrm{CHCOOH}-\mathrm{H}$, respectively, and $\mathrm{m}_{\mathrm{H}}, \mathrm{m}_{\mathrm{D}}, \mathrm{m}_{\mathrm{CH} 3 \mathrm{CHCOOH}}, \mathrm{m}_{\mathrm{CH} 3 \mathrm{CDCOOH}}$ are the molecular masses in $\mathrm{g} \mathrm{mol}^{-1}$ of $\mathrm{H}(1)$, D (2), $\mathrm{CH}_{3} \mathrm{CHCOOH}$ (73), and $\mathrm{CH}_{3} \mathrm{CDCOOH}$ (74), respectively. Combining equations (10) with

equation (9) then yields the maximum $\mathrm{KIE}=\frac{\mathrm{TOF}_{\mathrm{CH}_{3} \mathrm{CH}_{2} \mathrm{COOH}}}{\mathrm{TOF}_{\mathrm{CH}_{3} \mathrm{CD}_{2} \mathrm{COOH}}}$ is calculated to be 3.73. This value is considerably higher (by over a factor of two) than that observed experimentally, suggesting that $\alpha$-carbon dehydrogenation is not the only rate-controlling step.

\subsubsection{Secondary Kinetic Isotope Effect}

To estimate the maximum secondary KIE effect for labeled PAc assuming C-OH bond dissociation, we use Equation 9 with a C-OH bond frequency of $1360 \mathrm{~cm}^{-1}$ (which is the largest frequency observed in experimental studies [53] for carboxylic acids, which ranges from 1000 to $\left.1360 \mathrm{~cm}^{-1}\right)$. Next, the ratio of $v_{D}$ over $v_{H}$ can be approximated as:

$$
\frac{1}{\mu_{\mathrm{H}}}=\frac{1}{m_{\mathrm{OH}}}+\frac{1}{m_{\mathrm{CH}_{3} \mathrm{CH}_{2} \mathrm{CO}}} \text {, and } \frac{1}{\mu_{\mathrm{D}}}=\frac{1}{m_{\mathrm{OH}}}+\frac{1}{m_{\mathrm{CH}_{3} \mathrm{CD}_{2} \mathrm{CO}}}
$$

where $\mathrm{m}_{\mathrm{OH}}, \mathrm{m}_{\mathrm{CH} 3 \mathrm{CH} 2 \mathrm{CO}}, \mathrm{m}_{\mathrm{CH} 3 \mathrm{CD} 2 \mathrm{CO}}$ are the molecular masses of $\mathrm{OH}, \mathrm{CH}_{3} \mathrm{CH}_{2} \mathrm{CO}$, and $\mathrm{CH}_{3} \mathrm{CD}_{2} \mathrm{CO}$ which are 17,57 and $59 \mathrm{~g} / \mathrm{mol}$, respectively. As a result, the KIE for the secondary kinetic isotope effect is calculated to be 1.01 which is negligible.

\subsubsection{DFT and Microkinetic Modeling Study}

Our previous study analyzed the elementary reaction steps involved in the DCN and DCX of PAc on Pd (111) from first principles [22-24]. To computationally investigate the activity of labeled PAc, the adsorption and TS geometries obtained previously for unlabeled PAc were used. DFT frequency calculations were performed for all intermediates involved in the HDO of 
labeled PAc to obtain the frequencies of the labeled intermediates needed to compute the zeropoint energy corrections and vibrational partition functions of the labeled species. The calculated free energies of reaction $\left(\Delta \mathrm{G}_{\mathrm{rxn}}\right)$ and free energies of activation $\left(\mathrm{G}^{\star}\right)$ for all the labeled elementary reactions, as well as the reaction parameters for the corresponding unlabeled reactions, are listed in Table 2.

Previously, it was found $[22,23]$ that the dehydrogenation of the $\alpha$-carbon of PAc $\left(\mathrm{CH}_{3} \mathrm{CH}_{2} \mathrm{COOH}^{*}+2 * \rightarrow \mathrm{CH}_{3} \mathrm{CHCOOH}^{* *}+\mathrm{H}^{*}\right)$ is one of the rate-controlling steps. At $200^{\circ} \mathrm{C}$, this step has a free energy of reaction, $\Delta \mathrm{G}_{\mathrm{rxn}}$, of $-0.02 \mathrm{eV}$ and a free energy of activation of 0.70 $\mathrm{eV}$. The correspondent labeled reaction, i.e., the de-deuteriation of the $\alpha$-carbon of labeled PAc (Reaction 2: $\mathrm{CH}_{3} \mathrm{CD}_{2} \mathrm{COOH}^{*}+2 * \rightarrow \mathrm{CH}_{3} \mathrm{CDCOOH}^{* *}+\mathrm{D}^{*}$ ), has a free energy of reaction, $\Delta \mathrm{G}_{\mathrm{rxn}}$, of $-0.01 \mathrm{eV}$ and a free energy of activation of $0.77 \mathrm{eV}$ indicating that the overall turnover frequency (TOF) of labeled PAc will be slightly slower than that of unlabeled PAc as the barrier of this step was increased by nearly $0.1 \mathrm{eV}$.

To investigate the overall effects of changes in the reaction parameters on the TOFs, previously developed microkinetic models for the HDO of PAc over Pd (111) $[22,23]$ were applied to labeled and unlabeled PAc under the reaction conditions identical to the above experimental study (Section 3.1). Accordingly, simulations were carried out at $200^{\circ} \mathrm{C}$ and partial pressures of $\mathrm{H}_{2}$ and PAc of $0.05\left(5 \% \mathrm{H}_{2}\right)$ and $0.01\left(1 \%\right.$ PAc) bar, respectively. The partial pressures of $\mathrm{H}_{2} \mathrm{O}$, $\mathrm{CO}_{2}$ and $\mathrm{CO}$ were set to $10^{-3}$; however, the analysis shows that the microkinetic modeling result is insensitive to the partial pressures of these intermediates in the range of $10^{-4}$ to $10^{-2}$ bar. In doing so, the partial pressures of these products are fixed, which is necessary since the model does not contain a reaction network for the water-gas shift reaction. Finally, the primary kinetic 
Table 2. Reaction free energies $(\mathrm{eV})$, equilibrium and forward rate constants for all elementary reaction steps in the hydrodeoxygenation of labeled PAc over Pd (111) model surfaces at a temperature of $200^{\circ} \mathrm{C}$. For comparison reaction free energies and free energies of activation are also shown for unlabeled PAc. Note: * symbolizes a free site.

\begin{tabular}{|c|c|c|c|c|c|c|c|}
\hline \multirow[t]{2}{*}{ \# } & \multirow[t]{2}{*}{ Reaction } & \multicolumn{2}{|c|}{ Labeled PAc } & \multicolumn{2}{|c|}{$\begin{array}{l}\text { Unlabeled } \\
\text { PAc }\end{array}$} & \multirow{2}{*}{$\begin{array}{c}\text { Labeled } \\
\text { PAc } \\
\mathrm{K}_{\mathrm{eq}} \\
\end{array}$} & \multirow{2}{*}{$\begin{array}{c}\text { Labeled } \\
\text { PAc } \\
\mathrm{k}_{\text {forward }}\left(\mathrm{s}^{-1}\right)\end{array}$} \\
\hline & & $\Delta \mathrm{G}_{\mathrm{rxn}}$ & $\mathrm{G}^{*}$ & $\Delta \mathrm{G}_{\mathrm{rxn}}$ & $\mathrm{G}^{ \pm}$ & & \\
\hline 1 & $\begin{array}{l}\mathrm{CH}_{3} \mathrm{CD}_{2} \mathrm{COOH}^{*}+3^{*} \rightarrow \mathrm{CH}_{3} \mathrm{CD}_{2} \mathrm{CO}^{* * *} \\
+\mathrm{OH}^{*}\end{array}$ & 0.45 & 0.95 & 0.45 & 0.97 & $1.78 \times 10^{-5}$ & $7.30 \times 10^{2}$ \\
\hline 2 & $\begin{array}{l}\mathrm{CH}_{3} \mathrm{CD}_{2} \mathrm{COOH}^{*}+2^{*} \rightarrow \\
\mathrm{CH}_{3} \mathrm{CDCOOH}^{* *}+\mathrm{D}^{*}\end{array}$ & -0.01 & 0.77 & -0.02 & 0.70 & 1.25 & $6.95 \times 10^{4}$ \\
\hline 3 & $\mathrm{CH}_{3} \mathrm{CD}_{2} \mathrm{CO} * * * \rightarrow \mathrm{CH}_{3} \mathrm{CD}_{2} *+\mathrm{CO}^{*}+*$ & -0.68 & 0.99 & -0.68 & 1.02 & $1.85 \times 10^{7}$ & $2.58 \times 10^{2}$ \\
\hline 4 & $\mathrm{CH}_{3} \mathrm{CD}_{2} \mathrm{CO}^{* * *} \rightarrow \mathrm{CH}_{3} \mathrm{CDCO}^{* *}+\mathrm{D}^{*}$ & 0.07 & 0.89 & 0.04 & 0.84 & $1.99 \times 10^{-1}$ & $3.63 \times 10^{3}$ \\
\hline 5 & $\begin{array}{l}\mathrm{CH}_{3} \mathrm{CDCOOH}^{* *}+* \rightarrow \mathrm{CH}_{3} \mathrm{CDCO}^{* *}+ \\
\mathrm{OH}^{*}\end{array}$ & 0.23 & 0.88 & 0.23 & 0.87 & $2.83 \times 10^{-6}$ & $3.89 \times 10^{3}$ \\
\hline 6 & $\begin{array}{l}\mathrm{CH}_{3} \mathrm{CDCOOH}^{* *}+2^{*} \rightarrow \\
\mathrm{CH}_{2} \mathrm{CDCOOH}^{* * *}+\mathrm{H}^{*}\end{array}$ & -0.35 & 0.57 & -0.36 & 0.57 & $5.64 \times 10^{3}$ & $7.61 \times 10^{6}$ \\
\hline 7 & $\begin{array}{l}\mathrm{CH}_{3} \mathrm{CDCOOH}^{* *}+2^{*} \rightarrow \\
\mathrm{CH}_{3} \mathrm{CCOOH}^{* * *}+\mathrm{D}^{*}\end{array}$ & 0.01 & 1.21 & -0.03 & 1.16 & $7.88 \times 10^{-1}$ & 1.20 \\
\hline 8 & $\begin{array}{l}\mathrm{CH}_{3} \mathrm{CDCO}^{* *}+* * \mathrm{CH}_{3} \mathrm{CD}^{* *}+ \\
\mathrm{CO}^{*}\end{array}$ & -0.83 & 0.99 & -0.84 & 0.98 & $7.64 \times 10^{8}$ & $2.81 \times 10^{2}$ \\
\hline 9 & $\mathrm{CH}_{3} \mathrm{CDCO}^{* *}+2^{*} \rightarrow \mathrm{CH}_{3} \mathrm{CCO}^{* * *}+\mathrm{D}^{*}$ & -0.34 & 0.61 & -0.37 & 0.57 & $3.73 \times 10^{3}$ & $2.90 \times 10^{6}$ \\
\hline 10 & $\begin{array}{l}\mathrm{CH}_{3} \mathrm{CDCO}^{* *}+2^{*} \rightarrow \mathrm{CH}_{2} \mathrm{CDCO}^{* * *}+ \\
\mathrm{H}^{*}\end{array}$ & -0.26 & 0.58 & -0.27 & 0.58 & $6.57 \times 10^{2}$ & $6.69 \times 10^{6}$ \\
\hline 11 & $\begin{array}{l}\mathrm{CH}_{2} \mathrm{CDCOOH}^{* * *}+* \rightarrow \mathrm{CH}_{2} \mathrm{CDCO}^{* * *} \\
+\mathrm{OH}^{*}\end{array}$ & 0.61 & 1.22 & 0.61 & 1.22 & $3.30 \times 10^{-7}$ & $9.51 \times 10^{-1}$ \\
\hline 12 & $\begin{array}{l}\mathrm{CH}_{2} \mathrm{CDCOOH}^{* * *}+* \rightarrow \\
\mathrm{CHCDCOOH}^{* * *}+\mathrm{H}^{*}\end{array}$ & 0.06 & 0.91 & 0.06 & 0.91 & $2.17 \times 10^{-1}$ & $1.98 \times 10^{3}$ \\
\hline 13 & $\begin{array}{l}\mathrm{CH}_{3} \mathrm{CCOOH}^{* * *}+* \rightarrow \mathrm{CH}_{3} \mathrm{CCO} * * *+ \\
\mathrm{OH}^{*}\end{array}$ & 0.18 & 0.82 & N/A & N/A & $1.34 \times 10^{-2}$ & $1.75 \times 10^{4}$ \\
\hline 14 & $\mathrm{CH}_{3} \mathrm{CCO}^{* * *} \rightarrow \mathrm{CH}_{3} \mathrm{C}^{*}+\mathrm{CO}^{*}+*$ & -1.39 & 0.47 & N/A & N/A & $5.76 \times 10^{14}$ & $1.01 \times 10^{8}$ \\
\hline 15 & $\mathrm{CH}_{2} \mathrm{CDCO}^{* * *}+* \rightarrow \mathrm{CH}_{2} \mathrm{CD} * * *+\mathrm{CO}^{*}$ & -0.79 & 0.84 & -0.76 & 0.87 & $2.52 \times 10^{8}$ & $1.03 \times 10^{4}$ \\
\hline 16 & $\begin{array}{l}\mathrm{CH}_{2} \mathrm{CDCO}^{* * *}+2 * \rightarrow \mathrm{CHCDCO}^{* * * * *}+ \\
\mathrm{H}^{*}\end{array}$ & 0.01 & 0.68 & 0.00 & 0.68 & $8.79 \times 10^{-1}$ & $5.10 \times 10^{5}$ \\
\hline 17 & $\begin{array}{l}\mathrm{CHCDCOOH}^{* * *}+2 * \rightarrow \mathrm{CHCDCO}^{* * * * *} \\
+\mathrm{OH}^{*}\end{array}$ & 0.55 & 1.10 & 0.55 & 1.09 & $1.34 \times 10^{-6}$ & $2.03 \times 10^{1}$ \\
\hline 18 & $\mathrm{CHCDCO}^{* * * *} \rightarrow \mathrm{CHCD}^{* * *}+\mathrm{CO}^{*}$ & -1.11 & 0.59 & -1.11 & 0.57 & $7.16 \times 10^{11}$ & $4.93 \times 10^{6}$ \\
\hline 19 & $\mathrm{CHCH}^{* * *}+\mathrm{H}^{*} \rightarrow \mathrm{CH}_{2} \mathrm{CH}^{* * *}+*$ & 0.32 & 0.93 & N/A & N/A & $4.27 \times 10^{-4}$ & $1.34 \times 10^{3}$ \\
\hline 20 & $\mathrm{CH}_{2} \mathrm{CH}^{* * *}+\mathrm{H}^{*} \quad \rightarrow \mathrm{CH}_{2} \mathrm{CH}_{2} * *+2^{*}$ & -0.11 & 0.86 & N/A & N/A & $1.40 \times 10^{1}$ & $7.10 \times 10^{3}$ \\
\hline 21 & $\mathrm{CH}_{2} \mathrm{CH}^{* * *} \rightarrow \mathrm{CH}_{2} \mathrm{C}^{* *}+\mathrm{H}^{*}$ & -0.42 & 0.45 & N/A & N/A & $3.07 \times 10^{4}$ & $1.73 \times 10^{8}$ \\
\hline 22 & $\mathrm{CH}_{2} \mathrm{C}^{* *}+\mathrm{H}^{*} \rightarrow \mathrm{CH}_{3} \mathrm{C}^{*}+2^{*}$ & -0.27 & 0.87 & N/A & N/A & $8.27 \times 10^{2}$ & $5.44 \times 10^{3}$ \\
\hline 23 & $\mathrm{CH}_{2} \mathrm{CH}^{* * *}+\mathrm{H}^{*} \rightarrow \mathrm{CH}_{3} \mathrm{CH}^{* *}+2^{*}$ & 0.22 & 0.78 & N/A & N/A & $4.27 \times 10^{-3}$ & $4.81 \times 10^{4}$ \\
\hline 24 & $\mathrm{CH}_{3} \mathrm{C}^{*}+\mathrm{H}^{*} \rightarrow \mathrm{CH}_{3} \mathrm{CH}^{* *}$ & 0.92 & 1.11 & N/A & N/A & $1.68 \times 10^{-10}$ & $1.59 \times 10^{1}$ \\
\hline 25 & $\mathrm{CH}_{3} \mathrm{CH}^{* *}+\mathrm{H}^{*} \rightarrow \mathrm{CH}_{3} \mathrm{CH}_{2}^{*}+2^{*}$ & 0.12 & 0.85 & N/A & N/A & $5.45 \times 10^{-2}$ & $8.85 \times 10^{3}$ \\
\hline 26 & $\mathrm{CH}_{3} \mathrm{CH}_{2}^{*}+\mathrm{H}^{*} \rightarrow \mathrm{CH}_{3} \mathrm{CH}_{3} *+*$ & -0.03 & 0.64 & N/A & N/A & 2.20 & $1.64 \times 10^{6}$ \\
\hline
\end{tabular}




\begin{tabular}{|c|c|c|c|c|c|c|c|}
\hline 27 & $\mathrm{CH}_{3} \mathrm{CH}_{2} *+2^{*} \rightarrow \mathrm{CH}_{2} \mathrm{CH}_{2} * *+\mathrm{H}^{*}$ & -0.44 & 0.45 & N/A & N/A & $4.87 \times 10^{4}$ & $1.72 \times 10^{8}$ \\
\hline 28 & $\begin{array}{l}\mathrm{CH}_{3} \mathrm{CD}_{2} \mathrm{COOH}^{*}+2^{*} \rightarrow \\
\mathrm{CH}_{3} \mathrm{CD}_{2} \mathrm{COO}^{* *}+\mathrm{H}^{*}\end{array}$ & -0.35 & 0.35 & -0.34 & 0.43 & $5.10 \times 10^{3}$ & $1.68 \times 10^{9}$ \\
\hline 29 & $\mathrm{CH}_{3} \mathrm{CD}_{2} \mathrm{COO}^{* *} \rightarrow \mathrm{CH}_{3} \mathrm{CD}_{2}^{*}+\mathrm{CO}_{2} *$ & 0.17 & 1.41 & 0.16 & 1.37 & $1.62 \times 10^{-2}$ & $9.46 \times 10^{-3}$ \\
\hline 30 & $\begin{array}{l}\mathrm{CH}_{3} \mathrm{CD}_{2} \mathrm{COO}^{* *}+2 * \rightarrow \mathrm{CH}_{3} \mathrm{CDCOO}^{* * *} \\
+\mathrm{D}^{*}\end{array}$ & 0.47 & 1.33 & 0.44 & 1.28 & $9.30 \times 10^{-6}$ & $6.79 \times 10^{-2}$ \\
\hline 31 & $\begin{array}{l}\mathrm{CH}_{3} \mathrm{CDCOOH}^{* *}+* \rightarrow \mathrm{CH}_{3} \mathrm{CDCOO}^{* *} \\
+\mathrm{H}^{*}\end{array}$ & 0.13 & 0.85 & 0.12 & 0.84 & $3.79 \times 10^{-2}$ & $8.74 \times 10^{3}$ \\
\hline 32 & $\begin{array}{l}\mathrm{CH}_{3} \mathrm{CDCOOH}^{* *}+* \rightarrow \mathrm{CH}_{3} \mathrm{CD} * *+ \\
\mathrm{COOH}^{*}\end{array}$ & 0.31 & 1.40 & 0.40 & 1.38 & $4.64 \times 10^{-4}$ & $1.26 \times 10^{-2}$ \\
\hline 33 & $\mathrm{CH}_{3} \mathrm{CDCOO}^{* * *} \rightarrow \mathrm{CH}_{3} \mathrm{CD}^{* *}+\mathrm{CO}_{2} *$ & -0.39 & 0.89 & -0.39 & 0.92 & $1.43 \times 10^{4}$ & $3.16 \times 10^{3}$ \\
\hline 34 & $\begin{array}{l}\mathrm{CH}_{3} \mathrm{CDCOO}^{* * *}+* \rightarrow \mathrm{CH}_{3} \mathrm{CCOO}^{* * *}+ \\
\mathrm{D}^{*}\end{array}$ & -0.05 & 0.89 & -0.09 & 0.85 & 3.84 & $2.99 \times 10^{3}$ \\
\hline 35 & $\begin{array}{l}\mathrm{CH}_{3} \mathrm{CCOOH}^{* * *}+* \rightarrow \mathrm{CH}_{3} \mathrm{CCOO}^{* * *}+ \\
\mathrm{H}^{*}\end{array}$ & 0.07 & 1.01 & N/A & N/A & $1.85 \times 10^{-1}$ & $1.55 \times 10^{2}$ \\
\hline 36 & $\mathrm{CH}_{3} \mathrm{CCOOH}^{* * *} \rightarrow \mathrm{CH}_{3} \mathrm{C}^{*}+\mathrm{COOH}^{* *}$ & -0.58 & 0.98 & N/A & N/A & $1.65 \times 10^{6}$ & $3.29 \times 10^{2}$ \\
\hline 37 & $\begin{array}{l}\mathrm{CH}_{2} \mathrm{CDCOOH}^{* * *}+* \rightarrow \mathrm{CH}_{2} \mathrm{CD}^{* * *}+ \\
\mathrm{COOH}^{*}\end{array}$ & 0.45 & 1.79 & 0.75 & 2.10 & $1.78 \times 10^{-5}$ & $9.12 \times 10^{-7}$ \\
\hline 38 & $\mathrm{CH}_{3} \mathrm{CCOO}^{* * *} \rightarrow \mathrm{CH}_{3} \mathrm{C}^{*}+\mathrm{CO}_{2}^{*}+*$ & -1.13 & 0.64 & N/A & N/A & $1.15 \times 10^{12}$ & $1.65 \times 10^{6}$ \\
\hline 39 & $\mathrm{COOH}^{* *} \rightarrow \mathrm{CO}_{2}^{*}+\mathrm{H}^{*}$ & -0.57 & 0.37 & N/A & N/A & $1.09 \times 10^{6}$ & $1.07 \times 10^{9}$ \\
\hline 40 & $\mathrm{COOH}^{* *} \rightarrow \mathrm{CO}^{*}+\mathrm{OH}^{*}$ & -0.63 & 0.39 & N/A & N/A & $4.66 \times 10^{6}$ & $6.64 \times 10^{8}$ \\
\hline 41 & $\mathrm{OH}^{*}+\mathrm{H}^{*} \rightarrow \mathrm{H}_{2} \mathrm{O}^{*}+*$ & -0.28 & 0.66 & N/A & N/A & $1.06 \times 10^{3}$ & $9.00 \times 10^{5}$ \\
\hline
\end{tabular}


Table 2 (cont.)

\begin{tabular}{|c|c|c|c|c|c|c|c|}
\hline \multirow[t]{2}{*}{ \# } & \multirow[t]{2}{*}{ Reaction } & \multicolumn{2}{|c|}{ Labeled PAc } & \multicolumn{2}{|c|}{$\begin{array}{l}\text { Unlabeled } \\
\text { PAc }\end{array}$} & \multirow{2}{*}{$\begin{array}{l}\text { Labeled } \\
\text { PAc } \\
\qquad \mathrm{K}_{\mathrm{eq}}\end{array}$} & \multirow{2}{*}{$\begin{array}{l}\text { Labeled } \\
\text { PAc } \\
\mathrm{k}_{\text {forward }}\left(\mathrm{s}^{-1}\right)\end{array}$} \\
\hline & & $\Delta \mathrm{G}_{\mathrm{rxn}}$ & $\mathrm{G}^{+}$ & $\Delta \mathrm{G}_{\mathrm{rxn}}$ & $\mathrm{G}^{\ddagger}$ & & \\
\hline 42 & $\mathrm{CH}_{3} \mathrm{CD}^{* *}+\mathrm{H}^{*} \rightarrow \mathrm{CH}_{3} \mathrm{CDH}^{*}+2^{*}$ & 0.12 & 0.84 & 0.12 & 0.85 & $5.64 \times 10^{-2}$ & $1.05 \times 10^{4}$ \\
\hline 43 & $\mathrm{CH}_{3} \mathrm{CDH}^{*}+\mathrm{H}^{*} \rightarrow \mathrm{CH}_{3} \mathrm{CDH}_{2}^{*}+*$ & -0.03 & 0.63 & -0.03 & 0.64 & 2.35 & $1.79 \times 10^{6}$ \\
\hline 44 & $\mathrm{CH}_{2} \mathrm{CD}^{* * *}+\mathrm{H}^{*} \rightarrow \mathrm{CH}_{2} \mathrm{CDH}^{* *}+2^{*}$ & -0.10 & 0.86 & -0.11 & 0.86 & $1.15 \times 10^{1}$ & $7.46 \times 10^{3}$ \\
\hline 45 & $\mathrm{CH}_{2} \mathrm{CD}^{* * *}+\mathrm{H}^{*} \rightarrow \mathrm{CH}_{3} \mathrm{CD}^{* *}+2^{*}$ & 0.22 & 0.78 & 0.22 & 0.78 & $4.62 \times 10^{-3}$ & $4.71 \times 10^{4}$ \\
\hline 46 & $\mathrm{CH}_{3} \mathrm{CDH}^{*}+2^{*} \rightarrow \mathrm{CH}_{2} \mathrm{CDH}^{* *}+\mathrm{H}^{*}$ & -0.44 & 0.45 & -0.44 & 0.45 & $4.40 \times 10^{4}$ & $1.49 \times 10^{8}$ \\
\hline 47 & $\mathrm{CH}_{2} \mathrm{CDH}_{2} *+2^{*} \rightarrow \mathrm{CH}_{2} \mathrm{CDH}^{* *}+\mathrm{H}^{*}$ & -0.43 & 0.46 & -0.44 & 0.45 & $4.05 \times 10^{4}$ & $1.25 \times 10^{8}$ \\
\hline 48 & $\mathrm{CH}_{2} \mathrm{CDH}_{2} *+\mathrm{H}^{*} \rightarrow \mathrm{CH}_{3} \mathrm{CDH}_{2} *+*$ & -0.03 & 0.64 & -0.03 & 0.64 & 2.16 & $1.80 \times 10^{6}$ \\
\hline 49 & $\mathrm{CHCD}^{* * *}+\mathrm{H}^{*} \rightarrow \mathrm{CH}_{2} \mathrm{CD}^{* * *}+*$ & 0.32 & 0.93 & 0.32 & 0.93 & $4.00 \times 10^{-4}$ & $1.35 \times 10^{3}$ \\
\hline 50 & $\mathrm{CHCD}^{* * *}+\mathrm{H}^{*} \rightarrow \mathrm{CHCDH}^{* * *}+*$ & 0.32 & 0.93 & 0.32 & 0.93 & $4.25 \times 10^{-4}$ & $1.29 \times 10^{3}$ \\
\hline 51 & $\mathrm{CHCDH}^{* * *}+\mathrm{H}^{*} \rightarrow \mathrm{CHCDH}_{2}{ }^{* *}+2^{*}$ & 0.22 & 0.78 & 0.22 & 0.78 & $4.89 \times 10^{-3}$ & $4.84 \times 10^{4}$ \\
\hline 52 & $\mathrm{CHCDH}_{2} * *+\mathrm{H}^{*} \rightarrow \mathrm{CH}_{2} \mathrm{CDH}_{2} *+2^{*}$ & 0.12 & 0.85 & 0.12 & 0.85 & $5.46 \times 10^{-2}$ & $9.14 \times 10^{3}$ \\
\hline 53 & $\mathrm{CH}_{3} \mathrm{CD}_{2} *+\mathrm{H}^{*} \rightarrow \mathrm{CH}_{3} \mathrm{CD}_{2} \mathrm{H}^{*}+*$ & -0.03 & 0.63 & -0.03 & 0.64 & 2.29 & $1.88 \times 10^{6}$ \\
\hline 54 & $\mathrm{CH}_{3} \mathrm{CD}_{2} *+2^{*} \rightarrow \mathrm{CH}_{3} \mathrm{CD}^{* *}+\mathrm{D}^{*}$ & -0.09 & 0.77 & -0.12 & 0.73 & 8.20 & $6.22 \times 10^{4}$ \\
\hline 55 & $\mathrm{CH}_{3} \mathrm{CD}_{2} \mathrm{H}^{*}+* \rightarrow \mathrm{CH}_{3} \mathrm{CDH}^{*}+\mathrm{D}^{*}$ & 0.07 & 0.72 & 0.03 & 0.67 & $2.02 \times 10^{-1}$ & $2.33 \times 10^{5}$ \\
\hline 56 & $\mathrm{CH}_{2} \mathrm{CD}_{2} * *+2 * \rightarrow \mathrm{CH}_{2} \mathrm{CD}^{* * *}+\mathrm{D}^{*}$ & 0.99 & 0.13 & 0.11 & 0.97 & $3.96 \times 10^{-2}$ & $2.56 \times 10^{2}$ \\
\hline 57 & $\mathrm{CH}_{2} \mathrm{CD}^{* * *} \rightarrow \mathrm{CH}_{2} \mathrm{C}^{* *}+\mathrm{D}^{*}$ & -0.39 & 0.49 & -0.42 & 0.45 & $1.57 \times 10^{4}$ & $5.71 \times 10^{7}$ \\
\hline 58 & $\mathrm{CH}_{3} \mathrm{CD}^{* *} \rightarrow \mathrm{CH}_{3} \mathrm{C}^{*}+\mathrm{D}^{*}$ & -0.89 & 0.19 & -0.92 & 0.19 & $2.81 \times 10^{9}$ & $8.73 \times 10^{10}$ \\
\hline 59 & $\mathrm{CH}_{3} \mathrm{CD}_{2} \mathrm{COOH}+* \rightarrow \mathrm{CH}_{3} \mathrm{CD}_{2} \mathrm{COOH}^{*}$ & 0.76 & N/A & 0.74 & N/A & $8.85 \times 10^{-9}$ & $9.40 \times 10^{7}$ \\
\hline 60 & $\mathrm{CH}_{3} \mathrm{CH}_{3}+* \rightarrow \mathrm{CH}_{3} \mathrm{CH}_{3} *$ & 0.63 & N/A & N/A & N/A & $2.09 \times 10^{-7}$ & $1.50 \times 10^{8}$ \\
\hline 61 & $\mathrm{CH}_{2} \mathrm{CH}_{2}+2^{*} \rightarrow \mathrm{CH}_{2} \mathrm{CH}_{2} * *$ & -0.08 & N/A & N/A & N/A & 7.74 & $1.55 \times 10^{8}$ \\
\hline 62 & $\mathrm{H}_{2} \mathrm{O}+* \rightarrow \mathrm{H}_{2} \mathrm{O} *$ & 0.41 & N/A & N/A & N/A & 4.14 & $1.93 \times 10^{8}$ \\
\hline 63 & $\mathrm{CO}_{2}+* \rightarrow \mathrm{CO}_{2}^{*}$ & 0.74 & N/A & N/A & N/A & $1.33 \times 10^{-8}$ & $1.24 \times 10^{8}$ \\
\hline 64 & $\mathrm{CO}^{*} \rightarrow \mathrm{CO}+*$ & -1.19 & N/A & N/A & N/A & 828.13 & $1.55 \times 10^{8}$ \\
\hline 65 & $\mathrm{H}_{2}+2^{*} \rightarrow 2 \mathrm{H}^{*}$ & -0.58 & N/A & N/A & N/A & 6.04 & $5.80 \times 10^{8}$ \\
\hline 66 & $\mathrm{CH}_{3} \mathrm{CDH}_{2}+* \rightarrow \mathrm{CH}_{3} \mathrm{CDH}_{2} *$ & -0.63 & N/A & 0.63 & N/A & $2.19 \times 10^{-7}$ & $1.47 \times 10^{8}$ \\
\hline 67 & $\mathrm{CH}_{3} \mathrm{CD}_{2} \mathrm{H}+{ }^{*} \rightarrow \mathrm{CH}_{3} \mathrm{CD}_{2} \mathrm{H}^{*}$ & -0.63 & N/A & 0.63 & N/A & $1.76 \times 10^{-7}$ & $1.45 \times 10^{8}$ \\
\hline 68 & $\mathrm{CH}_{2} \mathrm{CDH}+2^{*} \rightarrow \mathrm{CH}_{2} \mathrm{CDH}^{* *}$ & -0.08 & N/A & -0.08 & N/A & 6.81 & $1.52 \times 10^{8}$ \\
\hline 69 & $\mathrm{CH}_{2} \mathrm{CD}_{2}+2^{*} \rightarrow \mathrm{CH}_{2} \mathrm{CD}_{2} * *$ & -0.08 & N/A & -0.08 & N/A & 6.90 & $1.50 \times 10^{8}$ \\
\hline 70 & $\mathrm{CHCD}+* \rightarrow \mathrm{CHCD}^{*}$ & -1.15 & N/A & -1.16 & N/A & $\frac{1.87 \times 10^{1}}{2}$ & $1.58 \times 10^{8}$ \\
\hline 71 & $\mathrm{HD}+2^{*} \rightarrow \mathrm{H}^{*}+\mathrm{D}^{*}$ & -0.57 & N/A & -0.58 & N/A & $1.24 \times 10^{6}$ & $4.73 \times 10^{8}$ \\
\hline
\end{tabular}


isotope effect, $\mathrm{KIE}=\frac{\mathrm{TOF}_{\mathrm{CH}_{3} \mathrm{CH}_{2} \mathrm{COOH}}}{\mathrm{TOF}_{\mathrm{CH}_{3} \mathrm{CD}_{2} \mathrm{COOH}}}$ was calculated to be 1.49 under the experimental reaction conditions. This value is in good agreement with our experimental result of 1.62 under the same reaction conditions. Table 3 summarizes and compares the KIE obtained based on the computational, calculated and experimental approach.

Table 3. Comparison of KIE values based on experimental, calculated and theoretical approaches. * Based on the upper limit for the primary kinetic isotope effect calculations discussed in Section 3.2.1.

\subsection{Extent of Dehydrogenation}

Given the confirmation of $\alpha$-carbon dehydrogenation as an important rate controlling step, the extent of this step under actual reaction conditions was further examined. Mass spectrometric analysis was performed on the reaction products formed for the HDO of labeled and unlabeled PAc, since GC cannot distinguish between various deuterium-labeled ethane products. Masses corresponding to $\mathrm{CH}_{3} \mathrm{CH}_{3}(\mathrm{~m} / \mathrm{e}=30), \mathrm{CH}_{3} \mathrm{CDH}_{2}(\mathrm{~m} / \mathrm{e}=31)$, and $\mathrm{CH}_{3} \mathrm{CD}_{2} \mathrm{H}(\mathrm{m} / \mathrm{e}=32)$ were considered. If one $\mathrm{C}$-D bond is broken at the rate-determining step, the product $\mathrm{CH}_{3} \mathrm{CDH}_{2}$ should be detected. Similarly, if two C-D bonds are broken at the rate-determining step, the product $\mathrm{CH}_{3} \mathrm{CH}_{3}$ is detected. Lastly, if there is no $\mathrm{C}-\mathrm{D}$ bond broken at the rate determining step, the product $\mathrm{CH}_{3} \mathrm{CD}_{2} \mathrm{H}$ is detected. The latter, however, was not able to be detected since it overlapped with a background of signal at $\mathrm{m} / \mathrm{e}=32$ arising from background $\mathrm{O}_{2}{ }^{+}$in the MS chamber. Nevertheless, it is highly unlikely that $\mathrm{CH}_{3} \mathrm{CD}_{2} \mathrm{H}$ species are formed, given that it 
requires $\mathrm{C}-\mathrm{C}$ bond breaking to occur to form a $\mathrm{CH}_{3} \mathrm{CD}_{2}$ fragment before $\mathrm{H}$ addition, which is not favorable. According to our DFT calculations (Table 2), the C-C bond dissociation in deuterated propanoyl (Reaction 3: $\mathrm{CH}_{3} \mathrm{CD}_{2} \mathrm{CO}^{* * *} \rightarrow \mathrm{CH}_{3} \mathrm{CD}_{2} *+\mathrm{CO}^{*}+*$ ) has an activation barrier of $0.99 \mathrm{eV}$, while the activation barrier of $\mathrm{C}-\mathrm{C}$ bond dissociation in Reaction $14\left(\mathrm{CH}_{3} \mathrm{CCO}^{* * *} \rightarrow\right.$ $\left.\mathrm{CH}_{3} \mathrm{C}^{*}+\mathrm{CO}^{*}+*\right)$ was lowered to $0.47 \mathrm{eV}$. This suggests that propionic acid or propanoyl most likely go through dehydrogenation steps prior to C-C bond dissociations. In this context, if $\mathrm{CH}_{3} \mathrm{CD}_{2} \mathrm{H}$ was a dominant product, no KIE would be observed; however, we observe a clear primary KIE.

Analysis of the mass spectrum recorded for the HDO of labeled PAc (Figure S2) shows that both $\mathrm{CH}_{3} \mathrm{CDH}_{2}$ and $\mathrm{CH}_{3} \mathrm{CH}_{3}$ are produced (see Supporting Information for detailed description). As can be seen from Table $\mathrm{S} 2$, the $\mathrm{CH}_{3} \mathrm{CDH}_{2}: \mathrm{CH}_{3} \mathrm{CH}_{3}$ ratio is 1:2. Thus, $\mathrm{C}-\mathrm{C}$ bond rupture in $\mathrm{CH}_{3}-$ $\mathrm{CH}_{2}-\mathrm{COOH}$ is favored by a factor of two after both $\mathrm{C}-\mathrm{H}$ bonds at the $\alpha-\mathrm{C}-\mathrm{H}$ position have been broken. These results also strongly support the idea that C-H bond-breaking occurs before C-C bond rupture.

\section{Conclusion}

Kinetic isotope effects in the HDO of deuterated PAc over Pd catalyst were examined with both experimental and computational approaches. Excellent agreement was found between the KIE found experimentally over $\mathrm{Pd} / \mathrm{C}\left(k_{\mathrm{H}} / k_{\mathrm{D}}=1.62\right)$ versus that estimated by DFT calculations coupled with microkinetic models for $\operatorname{Pd}(111)\left(k_{\mathrm{H}} / k_{\mathrm{D}}=1.49\right)$. The results confirm that the dehydrogenation of the $\alpha$-carbon in PAc is one of the rate-controlling steps, especially under lower partial pressures of hydrogen. In addition, measurements of product distribution suggest that the reaction proceeds through the decarbonylation pathway, and that the associated C-C rupture is most favorable after both of the $\alpha-\mathrm{C}-\mathrm{H}$ bonds are broken. These results reaffirm the 
advantage of isotope labeling experiments for elucidation of kinetically important steps in catalytic reactions. In particular, the coupling of experiments with modern computational modeling allows for a more detailed and deeper analysis than was previously possible. Further research will focus on similar types of combined studies to elucidate the reaction mechanism of HDO, as well as other reactions important to catalytic biomass conversion.

\section{Acknowledgements}

The authors wish to thank the financial support from National Science Foundation (NSF) grant number CHE-1153012. Computational resources have been provided by the National Energy Research Scientific Computing Center (NERSC) which is supported by the Office of Science of the U.S. Department of Energy and in part by the Extreme Science and Engineering Discovery Environment (XSEDE) provided by the Texas Advanced Computing Center (TACC) at the University of Texas at Austin under grant number TG-CTS090100. Finally, computing resources from USC NanoCenter and USC's High Performance Computing Group are gratefully acknowledged. Yuliana Lugo-José thanks the Sloan Foundation and the NSF Southeastern Alliance for Graduate Education and the Professoriate (SEAGEP) for financial support. The authors thank Professor Jim Ritter from the University of South Carolina for providing the Residual Gas Analyzer (RGA) equipment for the MS experiments.

Supporting Information Available: Experimental details with respect to the reactor system and mass spectroscopy measurements. This material is available free of charge via the Internet at http://www.sciencedirect.com. 


\section{References}

[1] Z. He, X. Wang, in: Novel Materials for Catalysis and Fuels Processing, American Chemical Society, 2013, pp. 301-329.

[2] D. Carpenter, T.L. Westover, S. Czernik, W. Jablonski, Green Chem., 16 (2014) 384-406.

[3] B.J. O’Neill, E.I. Gürbüz, J.A. Dumesic, J. Catal., 290 (2012) 193-201.

[4] E.W. Ping, J. Pierson, R. Wallace, J.T. Miller, T.F. Fuller, C.W. Jones, Appl. Catal., A, 396 (2011) 85-90.

[5] I. Simakova, O. Simakova, P. Mäki-Arvela, A. Simakov, M. Estrada, D.Y. Murzin, Appl. Catal., A, 355 (2009) 100-108.

[6] H. Bernas, K. Eränen, I. Simakova, A.-R. Leino, K. Kordás, J. Myllyoja, P. Mäki-Arvela, T. Salmi, D.Y. Murzin, Fuel, 89 (2010) 2033-2039.

[7] D.Y. Murzin, M. Snare, I. Kubickova, P. Maki-Arvela, K. Eranen, J. Warna, Chem Eng J, 134 (2007) 29-34.

[8] S. Lestari, I. Simakova, A. Tokarev, P. Mäki-Arvela, K. Eränen, D. Murzin, Catal. Lett., 122 (2008) 247-251.

[9] S. Lestari, P. Mäki-Arvela, I. Simakova, J. Beltramini, G. Lu, D. Murzin, Catal. Lett., 130 (2009) 48-51.

[10] M. Chia, J.A. Dumesic, Chem. Commun., 47 (2011) 12233-12235.

[11] K. Jacobson, K.C. Maheria, A. Kumar Dalai, Renew Sust Energ Rev, 23 (2013) 91-106.

[12] M. Mohammad, T. Kandaramath Hari, Z. Yaakob, Y. Chandra Sharma, K. Sopian, Renew Sust Energ Rev, 22 (2013) 121-132.

[13] E. Furimsky, Catal. Today, 217 (2013) 13-56.

[14] T.N. Pham, D. Shi, D.E. Resasco, Appl. Catal., B, 145 (2014) 10-23.

[15] P.i. Ma $\square$ ki-Arvela, B. Rozmysłowicz, S. Lestari, O. Simakova, K. Era $\square$ nen, T. Salmi, D.Y. Murzin, Energy \& Fuels, 25 (2011) 2815-2825.

[16] Y.K. Lugo-José, J.R. Monnier, C.T. Williams, Appl. Catal., A, 469 (2014) 410-418.

[17] S. Lestari, P.i. Ma $\square$ ki-Arvela, H. Bernas, O. Simakova, R. Sjo $\square$ holm, J. Beltramini, G.Q.M. Lu, J. Myllyoja, I. Simakova, D.Y. Murzin, Energy Fuels, 23 (2009) 3842-3845.

[18] E.W. Ping, R. Wallace, J. Pierson, T.F. Fuller, C.W. Jones, Microporous Mesoporous Mater., 132 (2010) 174-180.

[19] M. Snare, I. Kubic $\square$ ková, P. Mäki-Arvela, K. Eränen, D.Y. Murzin, Ind. Eng. Chem. Res., 45 (2006) 5708-5715.

[20] R.W. Carr, Chapter 3 Elements of Chemical Kinetics, in: W.C. Robert (Ed.) Comprehensive Chemical Kinetics, Elsevier, 2007, pp. 43-99.

[21] G.B. Marin, G.S. Yablonsky, Kinetics of chemical reactions : decoding complexity, WileyVCH, Weinheim, Germany, 2011.

[22] S. Behtash, J. Lu, M. Faheem, A. Heyden, Green Chem., 16 (2014) 605-616.

[23] J.M. Lu, S. Behtash, M. Faheem, A. Heyden, J. Catal., 305 (2013) 56-66.

[24] J.M. Lu, S. Behtash, A. Heyden, J. Phys. Chem. C, 116 (2012) 14328-14341.

[25] Y.K. Lugo-Jose, J.R. Monnier, A. Heyden, C.T. Williams, Catal. Sci. Tech., 4 (2014) 39093916.

[26] V. Pallassana, M. Neurock, J. Catal., 209 (2002) 289-305.

[27] H. Olcay, L.J. Xu, Y. Xu, G.W. Huber, Chemcatchem, 2 (2010) 1420-1424.

[28] J.L. Davis, M.A. Barteau, Surf. Sci., 256 (1991) 50-66.

[29] J.L. Davis, M.A. Barteau, Langmuir, 5 (1989) 1299-1309.

[30] W.F. Maier, W. Roth, I. Thies, P.V.R. Schleyer, Chem. Ber., 115 (1982) 808-812. 
[31] H.H. Lamb, L. Sremaniak, J.L. Whitten, Surf. Sci., 607 (2013) 130-137.

[32] K. Tamaru, Dynamic Relaxation Methods in Heterogeneous Catalysis, in: J.R. Anderson, M. Boudart (Eds.) Catalysis, Springer Berlin Heidelberg, 1991, pp. 87-129.

[33] M. Neurock, AIChE Journal, 40 (1994) 1085-1087.

[34] J. Happel, Isotopic assessment of heterogeneous catalysis, Academic Press, 1986.

[35] J. Sommer, S. Walspurger, ChemInform, 38 (2007) 1-29.

[36] G.C. Bond, J.J. Philipson, P.B. Wells, J.M. Winterbottom, Trans. Faraday Soc., 62 (1966) 443-454.

[37] H. Eyring, M. Polanyi, Zeitschrift Fur Physikalische Chemie-Abteilung B-Chemie Der Elementarprozesse Aufbau Der Materie, 12 (1931) 279-311.

[38] J. Bigeleisen, M.G. Mayer, J. Chem. Phys, 15 (1947) 261-267.

[39] F.J. Winkler, Angew. Chem., 93 (1981) 220-220.

[40] R. Van Hardeveld, F. Hartog, Surf. Sci., 15 (1969) 189-230.

[41] G. Kresse, J. Hafner, Phys. Rev. B, 48 (1993) 13115-13118.

[42] G. Kresse, J. Hafner, in: Phys. Rev. B, 1993, pp. 558-561.

[43] G. Kresse, J. Furthmuller, Comput. Mater. Sci., 6 (1996) 15-50.

[44] G. Kresse, D. Joubert, Phys. Rev. B 59 (1999) 1758-1775.

[45] J.P. Perdew, W. Yue, Phys. Rev. B, 33 (1986) 8800-8802.

[46] J.P. Perdew, Y. Wang, Phys. Rev. B, 45 (1992) 13244-13249.

[47] F. Jensen, Introduction to computational chemistry, Wiley, 1999.

[48] G. Buzzi-Ferraris, "BzzMath: Numerical libraries in C++", Politecnico di Milano: www.chem.polimi.it/homes/gbuzzi.

[49] C. Stegelmann, A. Andreasen, C.T. Campbell, J. Am. Chem. Soc., 131 (2009) 13563-13563.

[50] D.G. Truhlar, B.C. Garrett, S.J. Klippenstein, J. Phys. Chem., 100 (1996) 12771-12800.

[51] D.G. Truhlar, W.L. Hase, J.T. Hynes, J. Phys. Chem., 87 (1983) 2664-2682.

[52] H. Eyring, J. Chem. Phys, 3 (1935) 107-115.

[53] R.A. Tomasi, A Spectrum of Spectral Problems: Supplement, Sunbelt R \& T, Incorporated, 1994. 